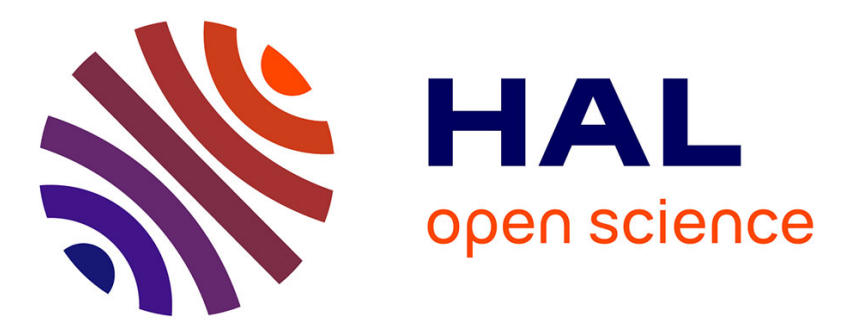

\title{
Five year monitoring of curing solutions of heat-cured mortars affected by delayed ettringite formation
}

\author{
Jean-Emmanuel Aubert, Gilles Escadeillas, Ali-Nordine Leklou
}

\section{To cite this version:}

Jean-Emmanuel Aubert, Gilles Escadeillas, Ali-Nordine Leklou. Five year monitoring of curing solutions of heat-cured mortars affected by delayed ettringite formation. Advances in Cement Research, 2013, 25 (3), pp.155-163. 10.1680/adcr.11.00069 . hal-01006904

\section{HAL Id: hal-01006904 https://hal.science/hal-01006904}

Submitted on 5 Mar 2017

HAL is a multi-disciplinary open access archive for the deposit and dissemination of scientific research documents, whether they are published or not. The documents may come from teaching and research institutions in France or abroad, or from public or private research centers.
L'archive ouverte pluridisciplinaire HAL, est destinée au dépôt et à la diffusion de documents scientifiques de niveau recherche, publiés ou non, émanant des établissements d'enseignement et de recherche français ou étrangers, des laboratoires publics ou privés. 


\section{Five year monitoring of curing solutions of heat-cured mortars affected by delayed ettringite formation}

\author{
Jean-Emmanuel Aubert \\ Université de Toulouse; UPS, INSA; LMDC (Laboratoire Matériaux et \\ Durabilité des Constructions), Toulouse Cedex, France \\ Gilles Escadeillas \\ Université de Toulouse; UPS, INSA; LMDC (Laboratoire Matériaux et \\ Durabilité des Constructions), Toulouse Cedex, France
}

\author{
Nordine Leklou \\ LUNAM Université, Université de Nantes - POLYTECH NANTES; GeM, \\ UMR CNRS 6183 - Research Institute on Civil Engineering and \\ Mechanics, IUT Saint-Nazaire, Saint-Nazaire Cedex, France
}

The work presented in this paper studies the leaching of heat-cured mortars affected by delayed ettringite formation (DEF). For this, the expansion and the leaching of various elements $\left(\mathrm{OH}^{-}, \mathrm{Ca}^{2+}, \mathrm{Na}^{+}\right.$and $\left.\mathrm{K}^{+}\right)$were monitored for more than 5 years in three mortars: a reference mortar and two compositions in which $3 \cdot 11 \%$ of $\mathrm{Na}_{2} \mathrm{SO}_{4}$ (sodium sulfate) and $1.75 \%$ of $\mathrm{NaOH}$ (sodium hydroxide) were added to the mixture. The four mortars expanded but with different kinetics. pH, conductivity and leaching of calcium had the same global variation: a fast decrease during the first few days of curing, a strong increase after the beginning of the expansions and, lastly, a plateau of several months followed, or not (depending on the mixtures and the progress of the reaction), by a strong decrease in leaching. Finally, the results suggest that the reasons for DEF are not only related to the leaching of alkalis.

\section{Introduction}

Heat-induced internal sulfate attack (still commonly referred to as delayed ettringite formation (DEF)) has been studied since the pioneering articles of Heinz and Ludwig (1985) and much work has been carried out on this pathology. Most of the time, the objectives of these works have been to understand the mechanisms that occur during this DEF or to study the various factors that can affect the pathology. Among these factors, the temperature reached during the heat treatment, the role of the aggregates (size and nature), and the composition and characteristics of the binder $\left(\mathrm{SO}_{3}, \mathrm{C}_{3} \mathrm{~A}, \mathrm{Al}_{2} \mathrm{O}_{3}\right.$, alkali contents or surface area) have been studied most frequently. The main conclusions of these works were efficiently summarised by Taylor et al. (2001) and during the RILEM workshop on 'Internal sulfate attack and delayed ettringite formation' (Scrivener and Skalny, 2002).

More recently, researchers have tried to identify factors that could accelerate the appearance of this pathology, such as preliminary microcracking of the specimens (with mechanical or thermal origins) (Escadeillas et al., 2007; Pavoine et al., 2006a, 2006b; Petrov and Tagnit-hamou, 2004). For other researchers, these factors are necessary to the appearance of the phenomenon (Collepardi, 1997; Fu et al., 1994). In spite of numerous studies dealing with heat-induced internal sulfate attack, a consensus has still not appeared on the mechanisms that occur during this pathology, nor on the principal factors that control it. The role of the temperature, for example, still raises many questions.
Researchers agree that the higher the temperature is, the faster the appearance of the expansion occurs. Some studies were carried out on specimens treated at $100^{\circ} \mathrm{C}$ to accelerate the phenomena even though such temperatures are never reached in precast industries or inside massive pieces of concrete (Lawrence, 1995; Yang et al., 1996, 1999a, 1999b). The temperature threshold for the development of DEF remains unclear. Today, it seems that a consensus has been reached on a value of $70^{\circ} \mathrm{C}$, but a recent study on field concrete showed that heat-induced internal sulfate attack developed in concrete whose temperature had not exceeded $60^{\circ} \mathrm{C}$ (Sahu and Thaulow, 2004). The authors explained this result by a combination of favourable factors: high cement content in the concrete, cement with large surface area, high alkali content, high sulfate content, high magnesium oxide content in the cement and high reactivity of the ferrite phase in the cement.

Many researchers have tried to link the chemical composition of the binder with the risk of $\mathrm{DEF}\left(\mathrm{C}_{3} \mathrm{~A}\right.$ content, $\mathrm{SO}_{3}$ content, $\mathrm{SO}_{3} /$ $\mathrm{Al}_{2} \mathrm{O}_{3}$ ratio and so on). More recently, Zhang and colleagues have proposed a $\mathrm{DEF}$ index calculated using $\mathrm{SO}_{3}, \mathrm{C}_{3} \mathrm{~A}$ and alkalis expressed in $\mathrm{Na}_{2} \mathrm{O}_{\text {eq }}$ contents. The significant role of alkalis in DEF is being highlighted more and more in numerous studies and, in particular, in a previous work by Escadeillas et al. (2007). Diamond, drawing his inferences from the works of Famy (1999) and Zhang (1999), has discussed the relevance of laboratory studies on DEF to DEF in field concretes (Diamond, 2000). He 
concludes that the immersion of samples during the laboratory tests strongly influences the appearance of DEF. According to his thinking, the formation of delayed ettringite would be triggered as a consequence of the leaching of alkali hydroxide, accelerated in the case of immersion of the samples. The results of a recent study on 5-year-old mortars stored in various conditions seem to confirm this theory (Aubert et al., 2009). In the same way, Taylor et al. (2001), in the conclusion of their review on DEF, criticise the traditional method of studying expansion in which bars of mortar or concrete made with different cements are cured in the same large tank. They propose that each sample should be placed in an individual container and that not only expansion but also the solution composition should be monitored.

Based on these discussions, the work presented in this paper aimed to study the leaching of heat-cured mortars affected by DEF. Special attention was paid to the case of the leaching of alkalis to verify Diamond's assumption. For this, the expansions and the solution compositions of three compositions of mortars were monitored during the conservation of the samples in deionised water for more than 5 years.

\section{Experiments}

Materials

The mortar specimens were prepared using an ordinary Portland cement (CEM I $52.5 \mathrm{R}$ type according to the NF EN 197-1 standard; NF, 2000) commonly employed in the precast industry. This cement is comparable to the ASTM type III cement that is, according to the literature, the cement most susceptible to DEF (Fu and Beaudoin, 1996; Grattan-Bellew, 2000; McDonald, 1998). The Blaine surface area of the cement was equal to $4200 \mathrm{~cm}^{2} / \mathrm{g}$. The siliceous aggregate was a French sand meeting standard NF EN 196-1 (NF, 2005). Such sand was chosen because the expansion is faster with siliceous aggregate than with limestone sand (Fu et al., 1997; Grattan-Bellew et al., 1998; Yang et al., 1996).

Three mixtures were tested: a reference mortar (C) and two compositions ( $\mathrm{CS}$ and $\mathrm{CN}$ ) in which $3 \cdot 11 \%$ (by weight of cement) of $\mathrm{Na}_{2} \mathrm{SO}_{4}$ (sodium sulfate) and $1.75 \%$ of $\mathrm{NaOH}$ (sodium hydroxide), respectively, were added to the mixture. So, the alkali contents of the mixtures $\mathrm{CS}$ and $\mathrm{CN}$ were equal. These two additions were dissolved in the mixing water before the preparation of the mortars. Table 1 presents the compositions of the three binders. The chemical composition of the cement $\mathrm{C}$ was measured using an atomic absorption spectrometer. The other two (CS and $\mathrm{CN}$ ) were computed using the composition of cement $\mathrm{C}$ and the amount of $\mathrm{NaOH}$ or $\mathrm{Na}_{2} \mathrm{SO}_{4}$.

The sand/cement ratio was 3 and the water/cement ratio was 0.5 in all the mixtures. Mortars were prepared according to standard NF EN 196-1 (NF, 2005). The mortar prisms were cast in $40 \times 40 \times 160 \mathrm{~mm}^{3}$ moulds equipped with embedded length measurement studs.

\section{Procedures}

After casting, the mortar specimens were cured according to the heat treatment presented in Figure 1. This heat treatment is representative of the treatments used in some precast industries.

The mortar specimens were cured in their metallic moulds, tightly covered by a metallic plate to prevent the evaporation of water during the heat treatment. The specimens were placed in a drying

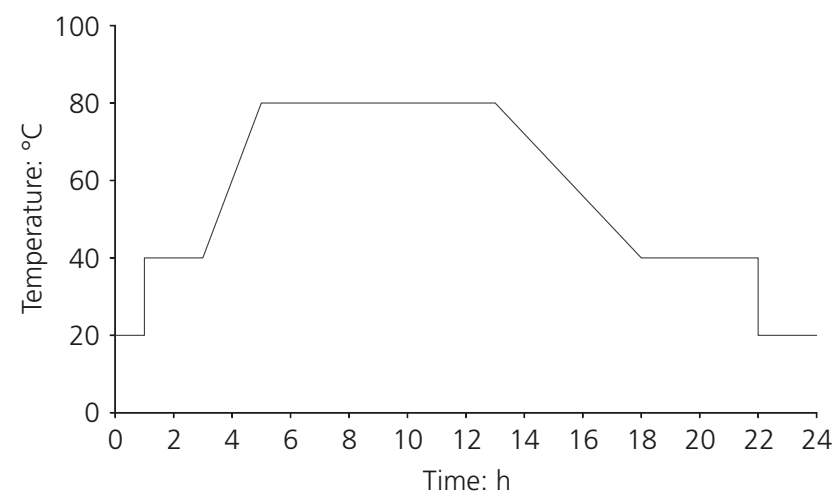

Figure 1. Temperature cycle imposed on the heat-cured mortars

\begin{tabular}{|c|c|c|c|}
\hline Components & $\begin{array}{l}\text { Cement } \\
\text { alone }\end{array}$ & $\begin{array}{c}\text { Cement }+3 \cdot 11 \% \\
\mathrm{Na}_{2} \mathrm{SO}_{4}\end{array}$ & $\begin{array}{c}\text { Cement }+1.75 \% \\
\mathrm{NaOH}\end{array}$ \\
\hline Reference & C & CS & \\
\hline Silicon dioxide $\left(\mathrm{SiO}_{2}\right): \%$ & $19 \cdot 3$ & $18 \cdot 7$ & $18 \cdot 9$ \\
\hline Aluminium oxide $\left(\mathrm{Al}_{2} \mathrm{O}_{3}\right): \%$ & $4 \cdot 6$ & $4 \cdot 4$ & $4 \cdot 5$ \\
\hline Iron (III) oxide $\left(\mathrm{Fe}_{2} \mathrm{O}_{3}\right): \%$ & $2 \cdot 2$ & $2 \cdot 2$ & $2 \cdot 2$ \\
\hline Calcium oxide $(\mathrm{CaO}): \%$ & $63 \cdot 9$ & $62 \cdot 0$ & $62 \cdot 8$ \\
\hline Magnesium oxide (MgO): \% & $2 \cdot 4$ & $2 \cdot 3$ & $2 \cdot 4$ \\
\hline Sulfur trioxide $\left(\mathrm{SO}_{3}\right): \%$ & $3 \cdot 3$ & 4.9 & $3 \cdot 2$ \\
\hline Potassium oxide $\left(\mathrm{K}_{2} \mathrm{O}\right): \%$ & $1 \cdot 1$ & $1 \cdot 0$ & $1 \cdot 0$ \\
\hline Sodium oxide $\left(\mathrm{Na}_{2} \mathrm{O}\right): \%$ & $0 \cdot 3$ & 1.6 & 1.6 \\
\hline
\end{tabular}

Table 1. Composition of the three binders (\% by weight) 
oven equipped with a temperature controller. Thermocouples were placed in the control specimen to verify the temperatures reached during the treatment. After cooling, the prisms were demoulded and stored at $20^{\circ} \mathrm{C}$ in sealed containers.

Four groups of three specimens were studied.

- C20: the mortar was prepared using the cement $\mathrm{C}$ and conserved at $20^{\circ} \mathrm{C}$ in frequently renewed deionised water.

- CN20: same conditions with the binder $\mathrm{CN}$.

- CS20: same conditions with the binder CS.

- CS40: same composition as the mixture CS20 but the temperature of conservation was different $\left(20^{\circ} \mathrm{C}\right.$ to $\left.40^{\circ} \mathrm{C}\right)$.

The main difference between the tests presented in this paper and those of the literature concerns the conditions of conservation of the samples. Instead of conserving the samples (sometimes of various compositions in order to save storage space) in tanks filled with water, the specimens of each composition were kept in closed tanks (in order to avoid evaporation of the curing solution and its significant carbonation) filled with deionised water with a liquid to solid ratio of 1.5. This curing water was analysed at each measurement of expansion and then totally renewed. During the tests, great precautions were taken to avoid polluting the specimens and thus the curing solutions. The analyses carried out on these curing solutions were: measurement of $\mathrm{pH}$, measurement of conductivity, measurements of sodium, potassium and calcium content using an atomic absorption spectrometer and measurement of sulfate content using a spectrophotocolorimeter (but only during the first 2 years). The concentrations of these elements were expressed in $\mathrm{mmol} / \mathrm{kg}$ (concentrations in mmol divided by the initial dry mass of the samples) instead of mmol/ 1 to allow comparison between the different mixtures, which did not have exactly the same initial masses.

\section{Results and discussion}

\section{Expansion of mortars}

Figure 2 presents the average values of the expansions measured on the four compositions of mortar. The error bars added to this graph show that the dispersion of the results was relatively low even though it increased during the acceleration of the expansions.

Figure 2 shows that the four compositions expanded but with different kinetics. Nevertheless, the forms of the curves are the same (sigmoid form as frequently observed in the literature), although it is a little early to conclude for the mixture $\mathrm{C}$ because it is still in the initial period of expansion. The expansion of mortar C (containing only cement) began very late (after more than 3 years). The fastest expansions were obtained with the addition of $\mathrm{Na}_{2} \mathrm{SO}_{4}$ (CS20 and CS40). Both mixtures began to expand after a few weeks but the development of the expansion was faster for the mortars stored at $40^{\circ} \mathrm{C}$. Finally, as was the case with $\mathrm{Na}_{2} \mathrm{SO}_{4}$, the addition of $\mathrm{NaOH}$ accelerated the appearance

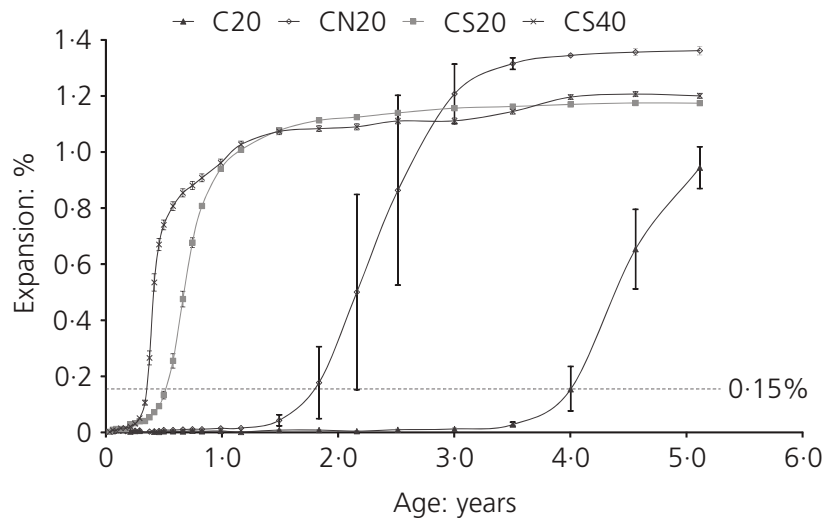

Figure 2. Expansion of mortars

of the expansion but to a lesser extent (the beginning of the expansion occurred after more than 1.5 years). Moreover, although the proportion of sulfates contained in CN20 was much weaker than that in CS20, the ultimate values of the expansions were comparable for these two mixtures. It thus seems that, from a certain proportion, a supplementary sulfate addition does not lead to greater expansion but only modifies the kinetics of the expansion.

A line corresponding to an expansion of $0 \cdot 15 \%$ has been added on Figure 2. This value corresponds to the expansion from which the first cracking can be observed. As commented before, the times to reach this value were very different according to the mixture considered: CS40 (125 days), CS20 (180 days), CN20 (670 days) and C20 (1460 days).

Microscopic examinations were carried out using a scanning electron microscope to verify that the formation of delayed ettringite was the cause of the expansion of the mortars. Scanning electron microscope observations (not included owing to need to limit the extent of the paper) confirmed that this expansion was ascribable to DEF and that no trace of alkali silica reaction was found in the various mixtures, and in particular in mixture CN20.

\section{$\mathrm{pH}$ and conductivity of curing solutions $\mathrm{pH}$}

Figure 3 presents the $\mathrm{pH}$ of the four curing solutions. $\mathrm{pH}$ decreased quickly during the first days of conservation for all the mixtures and then seemed to stabilise around values ranging between 11.8 and 12.1 except for three specific points corresponding to measurements at 302,361 and 425 days (when $\mathrm{pH}$ values were much lower for all the solutions). Considering that $\mathrm{pH}$ increased after 425 days for all the solutions, it is difficult to attribute this brutal fall to a physical or chemical phenomenon that could have occurred. It is possible that there was an experimental problem of measurement (change of electrode or problem with the standard solutions). This event will be recon- 


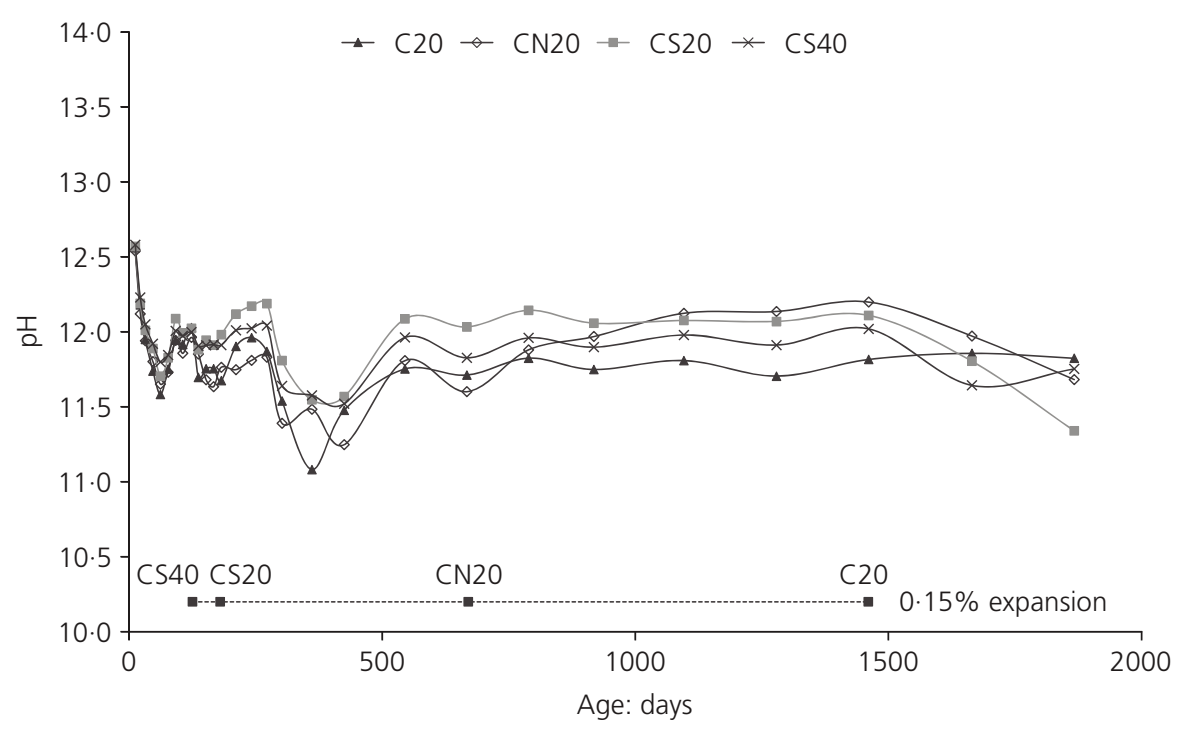

Figure 3. $\mathrm{pH}$ of curing solutions

sidered later in this paper with the analysis of the conductivity to see whether the assumption of an experimental problem proves to be correct.

The comparison of $\mathrm{pH}$ values between the various solutions shows that $\mathrm{pH}$ was systematically higher for the mixtures in which alkali was added ( $\mathrm{CN}$ and $\mathrm{CS}$ ) compared to the paste containing only cement $(\mathrm{C})$. Moreover, the increase in the curing temperature affected the $\mathrm{pH}$ of the solution slightly: the solution conserved at $40^{\circ} \mathrm{C}$ had a slightly lower $\mathrm{pH}$ than that conserved at $20^{\circ} \mathrm{C}$.

It is also interesting to compare the variation of $\mathrm{pH}$ with that of the expansions of the mortars: the increases of $\mathrm{pH}$ correspond to the beginning of the expansions (especially for the mixtures $\mathrm{CN}$ (after 670 days) and C (after 1460 days)). This result can be explained by the damage caused by the expansion: expansion produced cracking, which increased the surface of contact with the curing solution and thus facilitated the ionic exchanges and the dissolution of the portlandite, which was responsible for the leaching of hydroxyl. This significant increase in leaching caused by the cracking of the mortar was not easily observable for the mixtures containing $\mathrm{Na}_{2} \mathrm{SO}_{4}$ (CS20 and CS40) because it occurred rather early in the conservation (around 100 days) when leaching of the mortars was still significant.

Lastly, after a plateau of several years, $\mathrm{pH}$ decreased significantly for mixtures CN, CS20 and CS40. This decrease can be explained by the progressive reduction of the amount of portlandite accessible to the curing water.

To conclude this section on the $\mathrm{pH}$, it is possible to compare the measured values with those of the stability of ettringite. In a literature review, Shimada et al. (2005) suggest that the $\mathrm{pH}$ at which ettringite is stable ranges from $10 \cdot 6$ to 13 , drawing these conclusions essentially from the works of Damidot and Glasser (1992, 1993), who studied the phase changes in a $\mathrm{CaO}-\mathrm{Al}_{2} \mathrm{O}_{3}$ $\mathrm{CaSO}_{4}-\mathrm{H}_{2} \mathrm{O}$ system at $25^{\circ} \mathrm{C}, 50^{\circ} \mathrm{C}$ and $80^{\circ} \mathrm{C}$ by thermodynamic calculations. $\mathrm{pH}$ values of the curing solutions were always higher than the lower limit of stability of ettringite.

\section{Conductivity}

Figure 4 shows the values of the conductivity for each curing solution. The variation of the conductivity confirms the observations made previously for $\mathrm{pH}$

a fast decrease during the early days of curing

a strong increase corresponding to the beginning of the expansions ( $\mathrm{CN}$ after 700 days and $\mathrm{C}$ after 1500 days)

- no significant increase of conductivity for the mixture kept at $40^{\circ} \mathrm{C}$ in spite of the severe cracking of the specimens.

Moreover, the study of $\mathrm{pH}$ had shown that the $\mathrm{pH}$ decreased strongly for three dates, 302, 361 and 425 days, for all the solutions. The assumption of an experimental problem was proposed to explain these results. The absence of a corresponding reduction in conductivity tends to confirm this assumption.

\section{Leaching of major elements}

\section{Concentration of sulfate}

The sulfate contents of the solutions were only measured during the first 2 years and the results are presented in Figure 5. This figure shows that the concentrations of sulfate decreased quickly in all the solutions and became negligible after 200 days (below $0 \cdot 1 \mathrm{mmol} / \mathrm{kg}$ ). For this reason, the measurement was stopped after the first 2 years of conservation. 


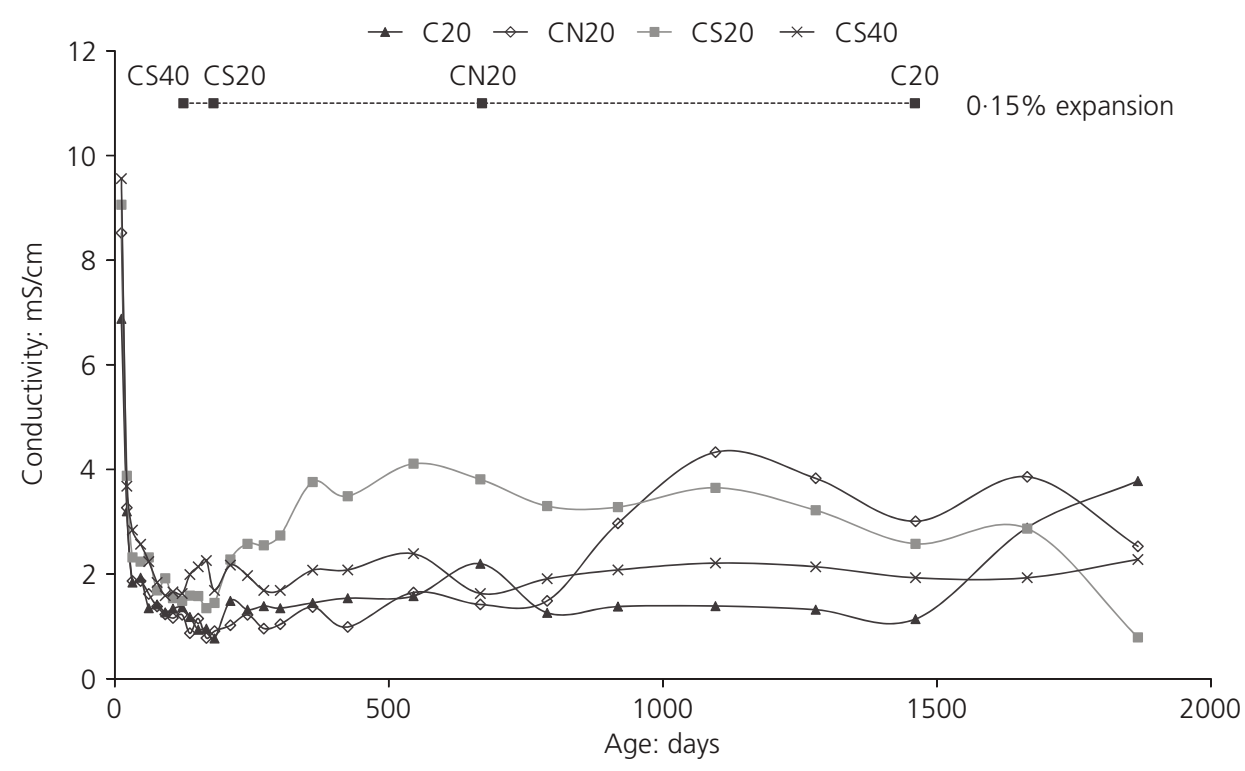

Figure 4. Conductivity of curing solutions

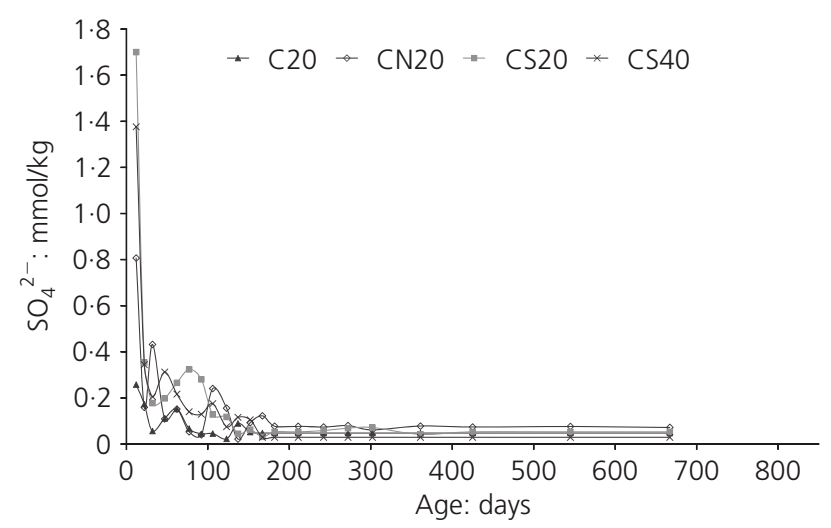

Figure 5. Concentrations of $\mathrm{SO}_{4}{ }^{2-}$ in curing solutions (in $\mathrm{mmol} / \mathrm{kg}$ )

\section{Concentration of calcium}

Figure 6 gives the concentrations of leached calcium in the curing solutions. As was the case for $\mathrm{pH}$, the leaching of calcium decreased quickly during the first days. After this time, in contrast to $\mathrm{pH}$, the variation of the curves was very different according to the solution considered.

- For the mixture CS20, there was a strong increase in the leaching of calcium, which corresponded to the beginning of the expansion of these mortars (approximately 100 days).

- The trend was the same, as previously noted with $\mathrm{pH}$, for the mixture CN20 (after 700 days) and the mixture C20 (after 1500 days).
Moreover, for the mixture containing $\mathrm{Na}_{2} \mathrm{SO}_{4}$ and conserved at $40^{\circ} \mathrm{C}(\mathrm{CS} 40)$, the increase in the leaching of calcium was much smaller than that for the same mixture conserved at $20^{\circ} \mathrm{C}$.

Lastly, as was the case for $\mathrm{pH}$, after a plateau of several months, the leaching of calcium decreased significantly for mixtures $\mathrm{CN} 20$ and CS20.

The comparison between the results of the mixtures CS20 and CS40 shows that the increase in curing temperature (from $20^{\circ} \mathrm{C}$ to $40^{\circ} \mathrm{C}$ ) reduced the leaching of calcium. This can be explained by the solubility of portlandite, which decreases when the temperature increases. However, Peycelon et al. (2006) have shown that, in spite of this reduction in the solubility of the portlandite, the increase in the diffusion coefficient of calcium with temperature leads to a global increase in leaching of calcium when the temperature increases from $20^{\circ} \mathrm{C}$ to $50^{\circ} \mathrm{C}$. This seems to be in contradiction with the results presented here, but the tests carried out in the two studies were very different on at least one point: the specimens studied by Peycelon et al. (2006) remained sound during their curing whereas, in the present study, the mortars containing $\mathrm{Na}_{2} \mathrm{SO}_{4}$ were strongly damaged very early in their curing. The concept of diffusion in a porous medium thus cannot be applied to the present case of study, and the increase in the accessibility of portlandite accentuated the effect of the temperature on the solubility of portlandite.

\section{Concentration of potassium}

As shown in Figure 7 (cumulated concentrations of potassium in curing solutions), potassium contained in the mortars was leached very quickly and the curing solutions of the various 


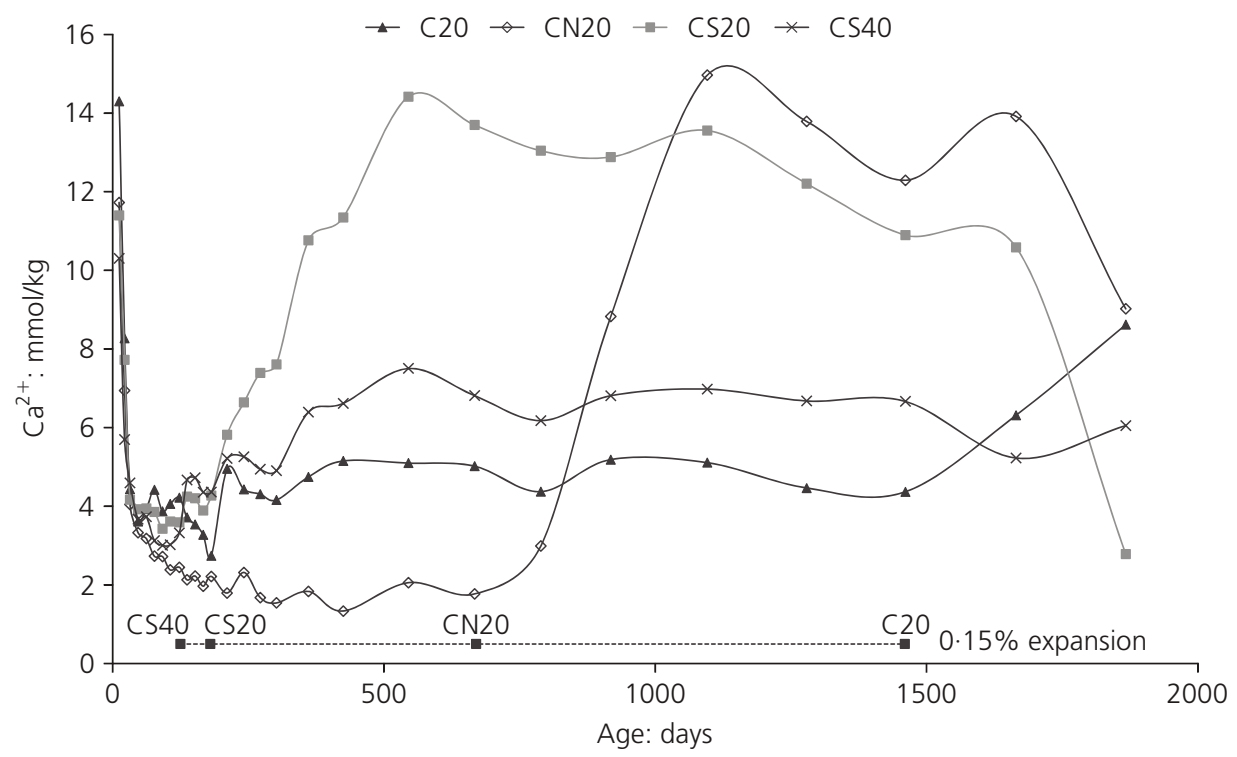

Figure 6. Concentrations of $\mathrm{Ca}^{2+}$ in curing solutions (in $\mathrm{mmol} / \mathrm{kg}$ )

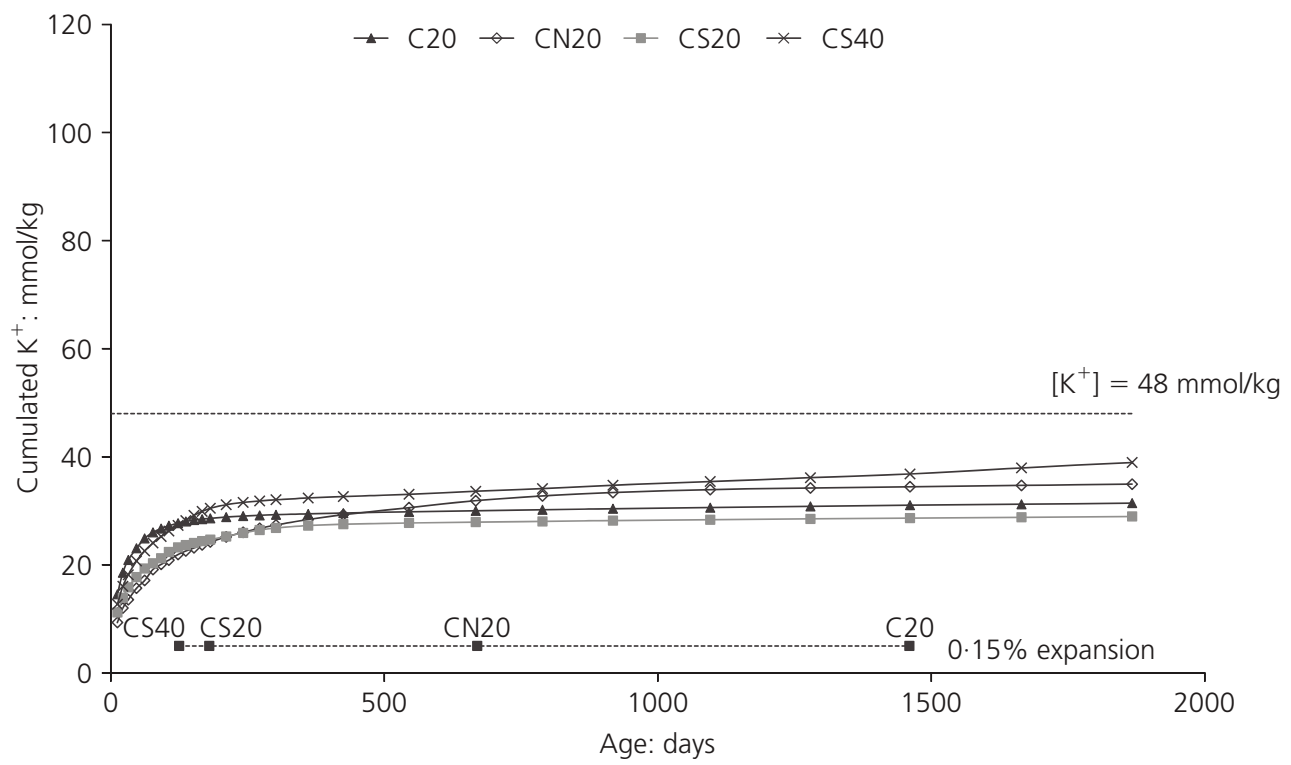

Figure 7. Cumulated concentrations of $\mathrm{K}^{+}$in curing solutions (in $\mathrm{mmol} / \mathrm{kg}$ )

mixtures showed identical behaviour. This was to be expected because all the mixtures had the same initial potassium content. Moreover, it appeared interesting to compare the quantities of leached potassium to the initial quantities contained in the mortars. The four mortars contained approximately equivalent proportions of potassium of about $48 \mathrm{mmol} / \mathrm{kg}$ (Figure 7). After 1870 days of leaching, the average cumulated leaching was approximately $35 \mathrm{mmol} / \mathrm{kg}$. This means that nearly $30 \%$ of the potassium initially contained in the mixtures still remained in the mortars.

\section{Concentration of sodium}

Figure 8 presents the cumulated concentrations of sodium in the curing solutions. The initial sodium content is also indicated in this figure: $115 \mathrm{mmol} / \mathrm{kg}$ for the mixtures CN20, CS20 and CS40 and $22 \mathrm{mmol} / \mathrm{kg}$ for the mixture $\mathrm{C} 20$. 


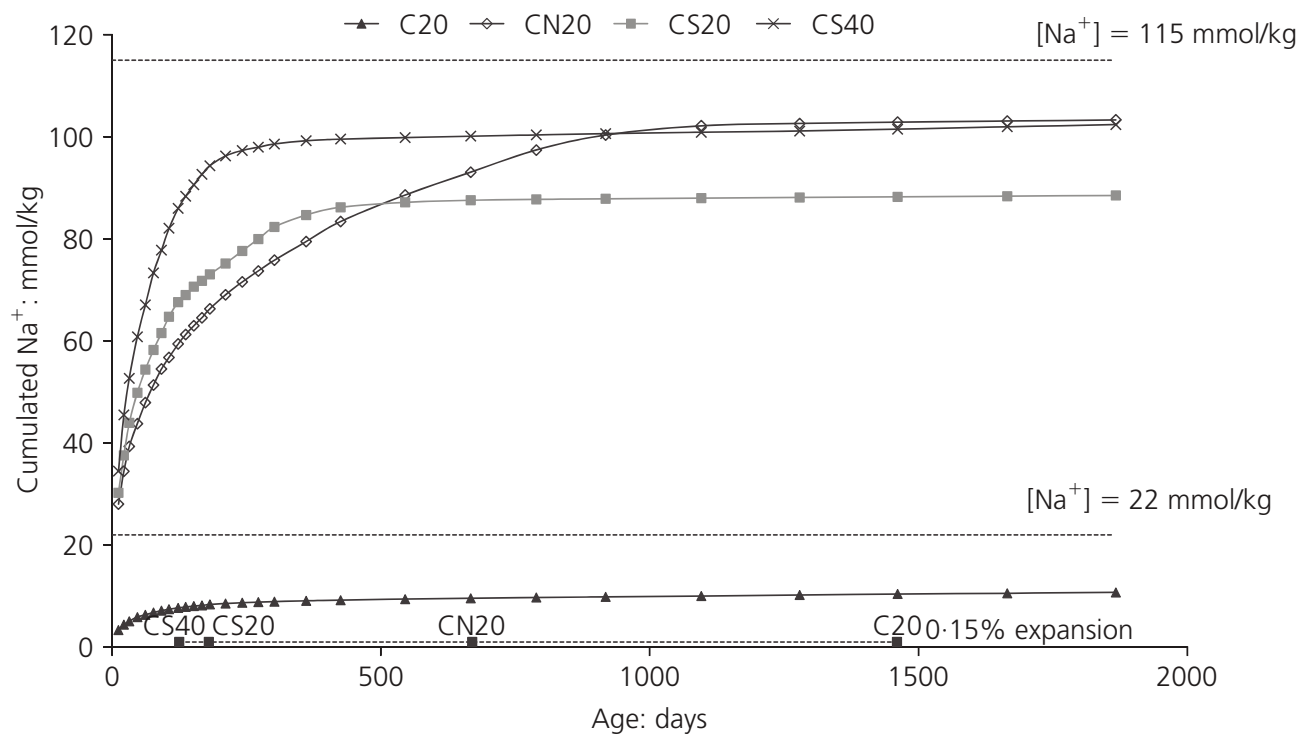

Figure 8. Cumulated concentrations of $\mathrm{Na}^{+}$in curing solutions

(in $\mathrm{mmol} / \mathrm{kg}$ )

Figure 8 shows that the ultimate cumulated concentration of sodium was similar (between 90 and $100 \mathrm{mmol} / \mathrm{kg}$ ) for all the mixtures to which sodium had been added (CS20, CS40 and CN). The main difference between these three mixtures was related to the kinetics of leaching.

Figure 8 highlights the fact that the increase of curing temperature accelerated the leaching of sodium for the mixtures CS. Many studies have shown that higher temperature significantly accelerates the diffusion of the elements contained in the pore solution, the majority of the authors modelling the effect of the temperature on the diffusion coefficient with an Arrhenius law: that is, with an exponential effect of the temperature. The results presented here confirm this in the case of sodium. In parallel with this result, the study of the expansion has shown that the beginning of the expansion is also accelerated when the cure temperature increases from $20^{\circ} \mathrm{C}$ to $40^{\circ} \mathrm{C}$ (Figure 2). These results could suggest that the faster the leaching of sodium is, the faster expansion appears in the mortar. This is in accordance with the conclusions of Diamond (2000), who proposed that the formation of delayed ettringite was triggered as a consequence of the leaching of alkali hydroxide. The role of alkalis in the development of DEF is still not very clear. It is possible that the local decrease of alkali concentration (and consequently the $\mathrm{pH}$ of the pore solution) destabilises chemical balances between sulfates adsorbed on C-S-H and the pore solution. This could lead to the desorption of sulfate from the C-S-H and, thus, to the precipitation of delayed ettringite. This is only an assumption and needs to be verified using experimental tests (such as analyses of the pore solution) or a thermodynamic equilibrium model of the pore solution.
In the case of the mixture with $\mathrm{NaOH}$ (CN20), the leaching of sodium was comparable to that of the mixture with $\mathrm{Na}_{2} \mathrm{SO}_{4}$. If we consider that the expansion of mortars is controlled by the leaching of alkalis, CN20 and CS20 should expand at the same time, which is absolutely not the case. However, the mixture CN20 contains much less sulfate than the mixture CS20, which may explain why the expansion of $\mathrm{CN} 20$ begins much more slowly. It thus suggests that there is a coupling between the sulfate content of cement and the concentration of free alkalis contained in the pore solution. The relation between the appearance of DEF and the leaching of alkalis can be explained by considering that the desorption of sulfates from the C-S-H would be possible only for a limited concentration of alkalis in the pore solution. Then, the more sulfates a mixture contains, the more easily they will be mobilised and the more quickly delayed ettringite will form, leading to expansion of the material.

Lastly, as was done for potassium, the quantities of leached sodium were compared to the initial concentrations contained in the mixtures. Except in the case of the mixture CS20, the quantity of sodium remaining in the mortars after 1900 days of leaching was the same for all the mortars. This quantity was not negligible (around $10 \mathrm{mmol} / \mathrm{kg}$ ), which showed, as observed for potassium, that a significant proportion of sodium was not leached even after a very long time of leaching (in the case of the reference mixture $\mathrm{C} 20$, the sodium remaining in the mixture was equal to $55 \%$ of the initial quantity). The fact that the remaining quantities of sodium were the same for the reference mixture and for the mixtures to which sodium had been added suggests that the remaining sodium came from the cement. The free alkalis 
added in the form to $\mathrm{Na}_{2} \mathrm{SO}_{4}$ or $\mathrm{NaOH}$ seem to have been totally leached during the curing of the mortars.

\section{Conclusions}

This study was carried out on four mortars: a reference mortar kept at $20^{\circ} \mathrm{C}(\mathrm{C} 20)$, two mortars in which $3 \cdot 11 \%$ of $\mathrm{Na}_{2} \mathrm{SO}_{4}$ was added to the mixtures, which were then kept at $20^{\circ} \mathrm{C}$ (CS20) and $40^{\circ} \mathrm{C}$ (CS40), and a mortar in which $1.75 \%$ of $\mathrm{NaOH}$ was added to the mixture, which was then kept at $20^{\circ} \mathrm{C}$. The expansion of the mortars and the leaching of various elements $\left(\mathrm{OH}^{-}, \mathrm{Ca}^{2+}\right.$, $\mathrm{Na}^{+}$and $\mathrm{K}^{+}$) were monitored for more than 5 years, which is relatively rare for this type of study and is original because no other data dealing with the leaching of heat-cured mortars affected by DEF have been published yet.

The main conclusions of this study are outlined below.

- The four compositions expanded but with different kinetics The expansion of the reference mortar $\mathrm{C} 20$ began very late (after more than 3 years). Both additions of $\mathrm{Na}_{2} \mathrm{SO}_{4}$ and $\mathrm{NaOH}$ accelerated the expansions but not to the same extent: CS20 and CS40 began to expand after a few weeks whereas the beginning of the expansion occurred after more than 1.5 years for $\mathrm{CN} 20$. Finally, the increase in the curing temperature (from $20^{\circ} \mathrm{C}$ to $40^{\circ} \mathrm{C}$ ) also accelerated the expansions.

- $\mathrm{pH}$, conductivity and leaching of calcium had the same global evolution:

- First, a fast decrease was observed during the first days of curing.

- Then, the leaching increased strongly, corresponding to the beginning of the expansions of the mortars (very early for CS20 and CS40, after 700 days for CN20 and after 1500 days for $\mathrm{C} 20$ ). This could be explained by the significant cracking of the mortars, which facilitated the penetration of the curing solution and thus increased the dissolution of soluble hydrates and especially portlandite.

- Lastly, a plateau of several months was observed and was followed, or not (depending on the mixtures and the progress of the reaction), by a strong decrease in leaching.

- One of the main aims of this work was to study the leaching of alkalis to check the assumption according to which DEF is triggered as a consequence of the leaching of alkali hydroxide. The case of potassium does not bring new information except for the high proportion of potassium that was not dissolved after more than 1800 days of immersion (30\% of the initial quantity).

For sodium, the results show that an increase in curing temperature accelerates both the leaching of sodium and the beginning of expansion, which could be in accordance with the previous assumption. The results obtained on the mixture with $\mathrm{NaOH}$ suggest that there is a coupling between the sulfate content of cement and the concentration of free alkalis contained in the pore solution. For the same alkali contents, the more sulfates a mixture contains, the more easily the sulfates will be mobilised and the more quickly delayed ettringite will form.

Even if these first results seem to confirm the assumption that DEF is triggered as a consequence of the leaching of alkali hydroxide, there are still numerous phenomena controlling the DEF that are not correctly explained. The phenomena related to DEF are complex and it seems that they are essentially linked to local chemical equilibrium conditions (pore solution in the neighbourhood of C-S-H). The experiments used in this work (global approach to the ionic exchanges between the materials and the curing solutions) constitute a first step towards understanding the mechanisms that control the reaction, but further experiments on a smaller scale are necessary to complete this study, such as extraction and analysis of the pore solution or the use of models, e.g. thermodynamic equilibrium of the pore solution.

To conclude, the results presented in this paper confirm the importance of the curing conditions for the appearance of DEF as pointed out in previous studies (Aubert et al., 2009; Famy, 1999). This has significant consequences on the recommendations for performing accurate laboratory tests on DEF as suggested by Taylor et al. (2001). According to these authors, the traditional method of studying expansion, in which bars of mortars or concrete made with many different cements are placed in the same large tank, is unsound. As was the case in the present paper, the authors suggest placing each sample in an individual container and monitoring not only the expansion but also the solution composition and anything else relevant. It is also necessary to control all the parameters that could have an effect on the leaching of the materials during the curing (composition of the curing solution, ratio between the volumes of the samples and of the curing solution, shape and size of the specimens and so on). These parameters are beginning to be considered in some recommendations, for example those published in France in the LCPC technical guide (LCPC, 2003), in which the solid to liquid ratio (by volume) should be controlled and set as close possible to $1 \cdot 5$. This is a first step but it is not sufficient and further recommendations (e.g. for eventual further standards concerning this pathology) should give these parameters serious consideration when putting forward accurate laboratory tests on DEF.

\section{REFERENCES}

Aubert JE, Escadeillas G and Leklou N (2009) Expansion of fiveyear-old mortars attributable to DEF: relevance of the laboratory studies on DEF? Construction and Building Materials 23: 3583-3585.

Collepardi M (1997) A holistic approach to concrete damage induced by delayed ettringite formation. Proceedings of Fifth CANMET/ACI International Conference on Superplasticizers and Other Chemical Admixtures in Concrete, Rome, Italy. 
Damidot D and Glasser FP (1992) Thermodynamic investigation of the $\mathrm{CaO}-\mathrm{Al}_{2} \mathrm{O}_{3}-\mathrm{CaSO}_{4}-\mathrm{H}_{2} \mathrm{O}$ system at $50^{\circ} \mathrm{C}$ and $85^{\circ} \mathrm{C}$. Cement and Concrete Research 22: 179-191.

Damidot D and Glasser FP (1993) Thermodynamic investigation of the $\mathrm{CaO}-\mathrm{Al}_{2} \mathrm{O}_{3}-\mathrm{CaSO}_{4}-\mathrm{H}_{2} \mathrm{O}$ system at $25^{\circ} \mathrm{C}$ and the influence of $\mathrm{Na}_{2} \mathrm{O}$. Cement and Concrete Research 23: $221-$ 238.

Diamond S (2000) The relevance of laboratory studies on delayed ettringite formation to DEF in field concretes. Cement and Concrete Research 30: 1987-1991.

Escadeillas G, Aubert JE, Segerer M and Prince W (2007) Some factors affecting delayed ettringite formation in heat-cured mortars. Cement and Concrete Research 37: 1445-1452.

Famy C (1999) Expansion of Heat-Cured Mortars. PhD thesis, Imperial College of Sciences, Technology and Medicine, University of London, UK.

Fu Y and Beaudoin JJ (1996) Mechanisms of delayed ettringite formation in Portland cement systems. ACI Materials Journal 93: 327-333.

Fu Y, Xie P, Gu P and Beaudoin JJ (1994) Significance of preexisting cracks on nucleation of secondary ettringite in steam cured cement paste. Cement and Concrete Research 24: 1015-1024.

Fu Y, Ding J and Beaudoin JJ (1997) Expansion of Portland cement mortar due to internal sulfate attack. Cement and Concrete Reasearch 27: 1299-1306.

Grattan-Bellew PE (2000) A discussion of the paper 'Delayed ettringite formation in heat-cured Portland cement mortars' by R Yang, CD Lawrence, CJ Lynsdale and JH Sharp. Cement and Concrete Research 30: 665-666.

Grattan-Bellew PE, Beaudoin JJ and Vallée VG (1998) Effect of aggregate particle size and composition on expansion of mortar bars due to delayed ettringite formation. Cement and Concrete Research 28: 1147-1156.

Heinz D and Ludwig U (1985) Mechanism of subsequent ettringite formation in mortars and concrete after heat treatment. Proceedings of 8th International Congress on Chemistry of Cement, Rio de Janeiro, Brazil, vol. 5, pp. 189-194.

Lawrence CD (1995) Mortar expansions due to delayed ettringite formation. Effects of curing period and temperature. Cement and Concrete Research 25: 903-914.

LCPC (2003) Aide à la gestion des ouvrages atteints de réactions de gonflement interne. Guide technique, techniques et méthodes de laboratoires des ponts et chaussés. La librairie du LCPC Editors.

McDonald D (1998) Delayed ettringite formation and heat curing
- implications of the work of Kelham. Cement and Concrete Research 28: 1827-1830.

NF (2000) EN 197-1: Cement - Part 1: Composition, specifications and conformity criteria for common cements. AFNOR, La Plaine Saint-Denis, France.

NF (2005) EN 196-1: Methods of testing cement. Determination of strength. AFNOR, La Plaine Saint-Denis, France.

Pavoine A, Divet L and Fenouillet S (2006a) A concrete performance test for delayed ettringite formation: Part I optimisation. Cement and Concrete Research 36: 2138-2143.

Pavoine A, Divet L and Fenouillet S (2006b) A concrete performance test for delayed ettringite formation: Part II validation. Cement and Concrete Research 36: 2144-2151.

Petrov N and Tagnit-hamou A (2004) Is microcracking really a precursor to delayed ettringite formation and consequent expansion? ACI Materials Journal 101: 442-447.

Peycelon H, Blanc C and Mazoin C (2006) Long term behaviour of concrete: influence of temperature and cement binders on the degradation (decalcification/hydrolysis) in saturated conditions. European Journal of Environmental and Civil Engineering 10: 1107-1125.

Sahu S and Thaulow N (2004) Delayed ettringite formation in Swedish concrete railroad ties. Cement and Concrete Research 34: 1675-1681.

Scrivener K and Skalny J (2002) Internal sulphate attack and delayed ettringite formation. Proceedings of the International RILEM TC 186-ISA Workshop (Scrivener K and Skalny J (eds)). RILEM Publications, Switzerland.

Shimada Y, Johansen VC, Miller FMG and Mason TO (2005) Chemical Path of Ettringite Formation in Heat-cured Mortar and its Relationship to Expansion: A Literature Review. RD136. Portland Cement Association, Skokie, Illinois, USA.

Taylor HFW, Famy C and Scrivener KL (2001) Delayed ettringite formation. Cement and Concrete Research 31: 683-693.

Yang R, Lawrence CD and Sharp JH (1996) Delayed ettringite formation in 4-year old cement pastes. Cement and Concrete Research 26: 1649-1659.

Yang R, Lawrence CD and Sharp JH (1999a) Effect of type of aggregate on delayed ettringite formation. Advances in Cement Research 11: 119-132.

Yang R, Lawrence CD, Lynsale CJ and Sharp JH (1999b) Delayed ettringite formation in heat-cured Portland cement mortar. Cement and Concrete Research 29: 17-25.

Zhang Z (1999) Delayed Ettringite Formation in Heat Cured Cementitious Systems. PhD thesis, School of Civil Engineering, Purdue University, USA. 